\title{
In Response: A Discussion of "Bulimia as a Masturbatory Equivalent"
}

\author{
C. Philip Wilson, MD
}

St. Luke's Roosevelt Hospital Center, Manhattan New York

Follow this and additional works at: https://jdc.jefferson.edu/jeffjpsychiatry

Part of the Psychiatry Commons

Let us know how access to this document benefits you

\section{Recommended Citation}

Wilson, MD, C. Philip (1986) "In Response: A Discussion of "Bulimia as a Masturbatory Equivalent"," Jefferson Journal of Psychiatry. Vol. 4 : Iss. 1 , Article 15.

DOI: https://doi.org/10.29046/JJP.004.1.013

Available at: https://jdc.jefferson.edu/jeffjpsychiatry/vol4/iss1/15

This Article is brought to you for free and open access by the Jefferson Digital Commons. The Jefferson Digital Commons is a service of Thomas Jefferson University's Center for Teaching and Learning (CTL). The Commons is a showcase for Jefferson books and journals, peer-reviewed scholarly publications, unique historical collections from the University archives, and teaching tools. The Jefferson Digital Commons allows researchers and interested readers anywhere in the world to learn about and keep up to date with Jefferson scholarship. This article has been accepted for inclusion in Jefferson Journal of Psychiatry by an authorized administrator of the Jefferson Digital Commons. For more information, please contact: JeffersonDigitalCommons@jefferson.edu. 


\title{
In Response
}

\section{A Discussion of "Bulimia As a Masturbatory Equivalent"}

\author{
C. Philip Wilson, M.D.
}

My research and that of my colleagues in the psychodynamic cause, structure and treatment of patients with bulimic anorexia nervosa correlates with and confirms the hypotheses presented by Levin (1) that bulimic symptoms may represent a masturbatory equivalent.

In our recently published book, Fear of Being Fat: The Treatment of Anorexia Nervosa and Bulimia (2) we confirmed Sperling's findings (3) that unresolved preoedipal fixations to the mother contribute to difficulties in psychosexual development and that anorexic girls and boys displace sexual and masturbatory conflicts from the genitals to the mouth.

Dr. Levin does not give us his concept of the classification and diagnosis of bulimia. He notes that his patient had an intense fear of gaining weight but he does not relate this fear to the overdetermined fear of being fat complex which I will briefly summarize before going on to discuss other aspects of Dr. Levin's paper.

During the past 30 years there has been increasing evidence that anorexia nervosa, a generic term which I use to include both the bulimic and restrictor syndromes, is a psychosomatic disorder (2-6). Specifically, the bulimic patient has strict but ineffective superego (moral) controls that are unable to regulate the impulse to eat. This defect in self-control is so threatening to the patient that the slightest gain in weight may produce panic, excessive exercising, starving, and vomiting. The bulimic patient, unable to control eating, is also unable to control other impulses, so that one sees sexual promiscuity, delinquency, stealing, lying, and running away more frequently than in the starving anorexic patient. This defect in ego and superego controls arises in part from identifying with parents who frequently argue, fight, and act out destructively more often than parents of starving anorexics.

Restrictor and bulimic anorexia nervosa are symptom complexes that occur in a variety of character disorders: hysterical, obsessive-compulsive, borderline,

C. Philip Wilson, M.D., a psychoanalyst, is senior attending psychiatrist and lecturer in psychosomatics at St. Luke's-Roosevelt Hospital Center in Manhattan. Dr. Wilson is a member of the faculties of the Columbia and New York University Psychoanalytic Institutes. 
and, in some cases, conditions close to psychosis. However, even in the most disturbed cases, there are areas of relatively intact ego functioning and a capacity for a transference relationship.

For the diagnosis of bulimic anorexia nervosa, gorging and vomiting as well as amenorrhea are necessary. Some cases begin with a restrictor anorexic syndrome and then develop bulimia. Other patients are predominantly restrictive in their eating behavior with infrequent episodes of bulimia. Many bulimics can keep their weight at near normal range by balancing their starving, gorging, vomiting, and laxative use.

I concur with Thoma's delineation of the syndrome: 1) the age of onset is usually puberty; 2) the patients are predominantly female; 3) the reduction in nutritional intake is psychically determined; 4) when spontaneous or selfinduced vomiting occurs the diagnosis of bulimia is made; 5) amenorrhea (which is psychically caused) generally appears either before or, more rarely, after the beginning of the weight loss; 6) constipation, sometimes an excuse for excessive consumption of laxatives, speeds up weight loss; 7) the physical effects of undernourishment are present, and, in severe cases, death may ensue ( 7 to $15 \%$ die) (6). Hogan (7) added three further observations: 1) there is commonly a tendency toward hyperactivity which may be extreme; 2) in females there is often a disproportionate loss of breast tissue early in the disease; and 3) the symptom complex is often accompanied by or alternates with other psychosomatic symptoms (or psychogenic equivalents such as depressions, phobias, or periods of self-destructive acting out that may include impulsive sexual behavior, stealing, or accident-prone behavior). With successful psychodynamic treatment, Wilson, Hogan and Mintz (2) have found that all the physical signs and symptoms of bulimic anorexia nervosa return to normal except for irreversible tooth and gum damage caused by gorging and vomiting. However, menstruation may not resume, even though the patient's weight returns to normal limits, if significant unconscious conflicts about pregnancy have not been resolved.

I recently presented hypotheses about the diagnosis, etiology, psychodynamics, and technique of treatment of anorexia nervosa (2). My research indicates that "fat phobia" should replace "anorexia" as a diagnostic term. These patients do not suffer from lack of hunger, but from the opposite, a fear of insatiable hunger as well as of impulses of many other kinds (2-6). Psychodynamic work with these restrictor and bulimic anorexics focused on their intense fear-of-being-fat body image disturbance, and their fear-of-being-fat complex. Neurotic analysands also evidenced less intensely cathected but clearcut fearof-being-fat obsessions and body image disturbances. These findings coupled with nonanalytic research lead to the conclusion that in our culture most women and certain men, those with unresolved feminine identifications, have a fear of being fat. Normal women readily admit to the fear. No matter how "perfect" a woman's figure may be, if she is told she is fat she will have an emotional reaction out of all proportion to reality. On the other hand, if she is told she looks thin or has lost weight, she will be inordinately pleased.

It is a central hypothesis of my research that restrictor and bulimic anorexia 
symptoms are caused by an overwhelming terror of being fat, which has been primarily caused by an identification with a parent or parents who have a similar fear of being fat, and that anorexia (fat phobia) is secondarily reinforced by the general irrational fear of being fat of most other women and many men in our culture.

\section{PSYCHODYNAMICS OF BULIMIC ANOREXIA NERVOSA}

In psychodynamic terms, this complex is rooted in unresolved sadomasochistic oral-phase conflicts that result in an ambivalent relationship with the mother. Fixation to this phase of development, with its accompanying fears of object loss, is caused by maternal and/or paternal overcontrol and overemphasis on food and eating functions as symbols of love. This unresolved conflict influences each subsequent maturational phase so that anal, oedipal, and later developmental conflicts remain unresolved.

The unresolved preoedipal fixation on the mother contributes to the difficulty in psychosexual development and the intensity of the oedipal development. Bulimic anorexia nervosa, fat phobia, can be considered a specific pathological outcome of unresolved oedipal conflicts in a child whose preoedipal relationship to the mother has predisposed her to this particular reaction under precipitating circumstances.

The genetic influences on this complex are parental conflicts about weight and food specifically and about aggressive and libidinal expression generally. In addition, the neurotic and/or addictive parents are perfectionistic, significantly denying the impact on the developing child of their exhibitionistic toilet, bedroom and other behavior. Other genetic factors are cultural, societal, and general medical influences, as well as secondary identification with women and/or men who share the fear-of-being-fat complex.

From an economic point of view, the unremitting pressure of repressed, unsublimated aggressive and libidinal drives, conflicts, and fantasies is a central issue for these inhibited patients. The terror of loss of control (i.e., of becoming fat) comprises the conscious fear of overeating and the unconscious fear of incorporating body parts, smearing or eating feces, bleeding to death, mutilating or being mutilated, or masturbating and/or becoming nymphomaniacal, which could result in orgastic pleasure.

All these feared drive eruptions are held in check by the terror of retaliatory punishment from the archaic sadistic superego. These conflicts are displaced onto and condensed into the fear of being fat. The defective bulimic ego is unable to contain impulses to gorge; there is a giving in to voraciousness and then an attempt at self-punishment and undoing by vomiting and/or the use of laxatives. In the bulimic there are also parallel attempts by the ego to suppress and repress libidinal and aggressive fantasies, drives and impulses; a surrender to these impulses and masochistic behavior which also expresses self-punishment and undoing.

From a structural point of view, ego considerations are central. In the 
preoedipal years, the ego of the bulimic anorexia-prone (fat-phobic) child becomes split. One part develops in a pseudonormal fashion: cognitive functions, the self-observing part of the ego, adaptive capacities, and other ego functions appear to operate normally. While the restrictor anorexics in childhood are most often described as "perfect" and have excellent records in school, the bulimic anorexics have more evidence of disobedience and rebellion at home and school. In adolescence there is more antisocial behavior, sexual promiscuity, and addiction. The ego represses, denies, displaces, externalizes, and projects conflicts onto the fear-of-being-fat complex. In many cases, conflicts are displaced onto habits such as thumbsucking, enuresis, encopresis, nailbiting, headbanging, and hairpulling. In other cases, there is a concomitant displacement and projection of conflict onto actual phobic objects. In some patients, bulimia anorexia alternates with other psychosomatic disease syndromes, such as ulcerative colitis (3), migrane (7) and asthma (8). This split in the ego manifests itself in the intense, psychotic-like denial of the displaced wishes, conflicts, and fantasies. In other words, the split-off neurotic part of the personality is denied in the fear-of-being-fat complex.

From an adaptive point of view, conflicts at each maturational and libidinal phase are denied, displaced, and projected onto the fear of being fat. Conflicts in separation-individuation are paramount and are denied by the parents and developing child $(9,10)$. Normal adaptive conflict is avoided and denied. Many parents of bulimics raise them in an unreal, overprotected world. Perfectionistic parents impair the ego's decision-making functions with their infantilizing intrusions into every aspect of their child's life. In each case a focus of therapy is on the pregenital object relations that have been caused by the unresolved parental relationships and conflicts in separation-individuation.

Unlike Sperling (3), I along with Hogan and Mintz (2) include males under the diagnostic category of anorexia nervosa. Mintz and Welsh (11) have shown that male bulimic anorexics have oedipal and preoedipal fixations and unresolved problems in separation-individuation, severe latent homosexual conflicts and a feminine identification, and the same fear-of-being-fat complex seen in the females, caused by an identification with the mother and/or the father's fear of being fat.

It is only possible to discuss a few aspects of Levin's rich clinical paper. I would concur with his observation (p. 34) that "the binge-purge cycle may also have helped her avoid the depression that might have been associated with her feelings of imperfection, lack of menses and inability to have intercourse and therefore to bear children." In the revised edition of our anorexia volume (2), I detail the central importance of analyzing the bulimic depression. In the chapter "Psychodynamic and/or Psychopharmacologic Treatment of Bulimic Anorexia Nervosa" I emphasize that psychoanalysis or analytic psychotherapy represent the most comprehensive approach to the treatment of restrictor and bulimic anorexics because their central focus is on the resolution of the underlying personality disorder. It may be appropriate in some cases to use medication, particularly antidepressants, to treat restrictive and bulimic anorexics. Such 
appropriate situations might include life-threatening electrolyte imbalances, severe states of starvation, treatment stalemates, or cases where cost and therapist availability are problems. However, the use of drugs may be a trade-off with potentially disadvantageous consequences.

In their eclectic volume on the psychotherapy of anorexia nervosa and bulimia, Garner and Garfinkel (12) conclude that medication remains a controversial issue. Studies of chlorpromazine, cyproheptadine, lithium, bromocryptine, naloxone, and cannabis showed that no single drug has a generalized application in the treatment of anorexia nervosa. Garner and Garfinkel note that the role of anticonvulsants in the treatment of bulimia is unclear. They emphasize that, of all drug treatments, the role of antidepressants remains the most hotly debated.

There have been an increasing number of reports of the use of antidepressants, particularly in the treatment of bulimic anorexics (13-23). In view of this development, I have: 1) explored the psychodynamics and etiology of the bulimic anorexic's depression; 2) outlined our psychoanalytic technique with bulimics and documented the psychoanalytic resolution of depressed affects in the course of treatment; and 3) described in detail the dangers, risks, and consequences of the use of medication.

The rationale for the use of antidepressant medications is that in some cases they achieve dramatic resolution of symptoms which seem related to the finding of affective disorder in the family (19). On the other hand, Altshuler and Weiner (24) seriously question the research methodology that links restrictor and bulimic anorexia nervosa to a family history of major depression. Whatever genetic, constitutional factors there are in bulimic anorexics (19) they do not preclude psychoanalytic treatment. Some of our cases would have been diagnosed as "endogenous depression"; however, they were analyzable. The parallel may be with asthmatics, some of whom have a constitutional genetic allergic predisposition. Such asthmatic patients can be successfully analyzed. After analysis they may still test positively for allergies, but they no longer experience asthmatic attacks in conflictual situations (3).

My central purpose here is to emphasize that bulimic anorexics suffer from an impulse disorder. Their fat phobia masks an addictive personality disorder. The goal of psychoanalytic treatment of the disorder is to strengthen the patients' ego so that they can tolerate both realistic and neurotic depression. Precipitous relief of depression by means of medication can lead to a loss of motivation for treatment if the etiological unconscious conflicts have not been resolved; bulimic symptomatology may be replaced by other psychosomatic symptoms such as asthma (25), or by other neurotic symptom formation, acting out, and/or suicidal impulses. A psychological addiction to medication can develop in such addiction-prone patients. Bulimic patients in "hyper states" may use any available substance, including medication, for suicidal purposes. This has been particularly noted in their overdosing themselves with laxatives (2).

The components of bulimic depression are overdetermined and are caused by unresolved oedipal and preoedipal conflicts. Among the important determi- 
nants are:

1. Unhappiness because of failure to achieve mature object relations.

2. Unhappiness and anger because of a failure to actualize magical narcissistic fantasies.

3. Unhappiness at adaptive failure.

4. Unhappiness because of failure to achieve normal separation-individuation from parents or parent surrogates.

5. Unhappiness because of failure to achieve the perfectionistic goals required by the archaic superego.

6. Unhappiness because of neurotic guilt inflicted by the archaic superego, which legislates against the expression of libidinal or aggressive impulses and fantasies.

In Levin's case the elimination of bulimic symptoms when the patient began to masturbate was in my experience the result of multiple factors in the therapeutic process. An important one probably was the modification of the strict archaic superego which is characteristic of these patients. In our Fear of Being Fat volume, Welsh described the resolution of bulimic anorexic symptoms in a male patient. His evaluation of his results could be applied to Levin's patient.

"It appears that the core conflict for patients with anorexia nervosa is the enormous fear of losing control over their impulses and forbidden wishes from all levels of development. The anxiety over controlling these impulses is displaced onto eating and the fear of being fat, with focal distortions of body image and impaired reality testing. An attempt is made to relieve the anxiety by the reassurance that eating and body weight can be mastered and controlled.

"The treatment of Martin demonstrates the complicated interplay of conflict, defense, fantasy, and disordered object relations in the pathogenesis of anorexia nervosa. It is difficult to imagine any treatment other than an intensive, analytically oriented individual psychotherapy or psychoanalysis that would be able to uncover and address the material that was revealed in this case. Interpretation and insight helped Martin to understand a good deal about the psychological causes of his unusual eating behavior. He achieved significant symptomatic improvement. He gained 45 pounds and stabilized at a normal weight. He modified his severe dieting and the whole cluster of typical anorexic behaviors related to the fear of becoming fat: vomiting, taking laxatives, and hyperactivity. He stopped being susceptible to bulimic episodes, and he resumed his usual masturbation practices.

"Most therapists interested in symptomatic or behavioral change would have considered Martin 'cured.' However, his therapist had hoped for a deeper resolution of his conflicts and for more ego growth. Nonetheless, there was some ego development that came from the insight and working through in the treatment. He understood enough about his feelings and conflicts so that he no longer feared an absolute loss of control. His impulses were not so frightening 
and potentially overwhelming. Martin was left with a greater sense of mastery that came from self-knowledge, rather than a false and pathological mastery of his eating and weight. With insight into his homosexual conflicts, rage, selfpunitiveness, and need for omnipotent control, his masochism became less severe and he was able to keep his job without provoking his boss into firing him. However, he was too afraid to venture further in treatment, which would have upset his schizoid, but stable, existence."

I have explored the technique of therapy of bulimia in our book. The technique of therapy advocated is intensive psychotherapy or analysis of the bulimic anorexic with conjoint therapy of the parents if necessary. In some cases the mother and/or the father need individual therapy to change their unhealthy relationship with their child. The focus in the first phase of analysis is on the dyadic transference, the failure to free associate, the patient's impulsivity, and use of denial and projective identification. Early interpretation of the patient's impulse disorder is advocated. Acting out, rationalization, withholding, and lying are more frequent defenses of the bulimic anorexic. Most patients are seen face to face in the first dyadic phase of treatment. The therapist is in charge of treatment with hospitalization reserved for true emergencies. Medication is contraindicated if psychotherapy or analysis is feasible.

\section{REFERENCES}

1. Levin E: Bulimia as a masturbatory equivalent. The Jefferson Journal of Psychiatry $3: 24-35,1985$

2. Wilson CP: Fear of Being Fat: The Treatment of Anorexia Nervosa and Bulimia (Revised Edition). Edited by Wilson CP, Hogan CC, Mintz IL. New York, Aronson, 1985

3. Sperling M: Anorexia Nervosa, Part 4, in Psychosomatic Disorders in Childhood. Edited by Sperling O. New York, Aronson, 1978

4. Thoma H: Anorexia Nervosa. New York, International Universities Press, 1967

5. Bruch H: The Golden Cage: The Enigma of Anorexia Nervosa. Cambridge, Harvard University Press, 1978

6. Sours JA: Starving to Death in a Sea of Objects: The Anorexia Nervosa Syndrome. New York, Aronson, 1980

7. Hogan CC: in Fear of Being Fat: The Treatment of Anorexia Nervosa and Bulimia (Revised Edition). Edited by Wilson CP, Hogan CC, Mintz IL. New York, Aronson, 1985

8. Mintz IL: in Fear of Being Fat: The Treatment of Anorexia Nervosa and Bulimia (Revised Edition). Edited by Wilson CP, Hogan CC, Mintz IL. New York, Aronson, 1985

9. Mushatt C: Mind-body environment: toward understanding the impact of loss on psyche and soma. Psychoanalytic Quarterly 44:81-106, 1975

10. Mushatt C: Anorexia nervosa: a psychoanalytic commentary. International Journal of Psychoanalytic Psychotherapy 9:257-265, 1982

11. Mintz IL, Welsh HK: Psychoanalytic therapy: the case of Martin, in Fear of Being 
Fat: The Treatment of Anorexia Nervosa and Bulimia (Revised Edition). Edited by Wilson CP, Hogan CC, Mintz IL. New York, Aronson, 1985

12. Garner DM, Garfinkel PE: Handbook of Psychotherapy for Anorexia Nervosa and Bulimia. New York, The Guilford Press, 1985

13. Brotman AW, Herzog DC, Woods SW: Antidepressant treatment of bulimia: the relationship between binging and depressive symptomatology. J Clin Psych 45:7-9, 1984

14. Jonas JM, Pope Jr HG, Hudson JI: Treatment of bulimia with MAO inhibitors. J Clin Psychopharmacology 3:59-60, 1983

15. McGrath PM, Quitkin FM, Steward JW, et al: An open clinical trial of mionserin. Am J Psych 138:530-532, 1981

16. Mendels J: Eating disorders and antidepressants. J Clin Psychopharmacology 3:59, 1983

17. Pope Jr HG, Hudson JI: Treatment of bulimia with antidepressants. Psychopharmacology 78:167-179, 1982

18. Pope Jr HG, Hudson JI, Jonas JM, et al: Bulimia treated with imipramine: a placebo-controlled double-blind study. Am J Psych 140:554-558, 1983

19. Pope Jr HG, Hudson JI: New Hope for Binge-eaters: Advances in the Understanding and Treatment of Bulimia. New York, Harper and Row, 1984

20. Sabine EJ, Yonace, Farrington AJ, et al: Bulimia nervosa: a placebo-controlled therapeutic trial of mianserin. Brit J Clin Pharmacology 15:195S-202S, 1983

21. Walsh BT, Stewart J, Wright L, et al: Treatment of bulimia with monoamine oxidase inhibitors. Am J Psych 139:1629-1630, 1982

22. Walsh BT, Stewart J, Wright L, et al: Treatment of bulimia with monoamine oxidase inhibitors. Presented at the Annual Meeting, American Psychiatric Association, May 1983

23. Walsh BT, Stewart JW, Roose SP, et al: Treatment of bulimia with phenelzine: a double-blind placebo controlled study. Arch Gen Psych 41:1105-1109, 1984

24. Altshuler KZ, Weiner MF: Anorexia nervosa and depression: a dissenting view. Am J Psych 3:328-332, 1985

25. Mintz IL: Multideterminism in asthmatic disease. Int J Psychoanalytic Psychotherapy $8: 593-600,1980$ 